\title{
EDITORIAL
}

\section{Fecal occult blood testing while waiting for screening colonoscopy in average-risk individuals: Durable option or short-term solution?}

\author{
Steven J Heitman MD MSc FRCPC
}

\begin{abstract}
A $s$ the second leading cause of cancer mortality, colorectal cancer (CRC) is an important health issue. CRC fulfills the WHO criteria for mass screening (1). Furthermore, clinical practice guidelines have broadly endorsed CRC screening (2-5) and, for average-risk individuals, have generally supported choice among the available screening options. Nevertheless, CRC screening uptake remains disappointingly low (6).

Population-based CRC screening programs are on the rise internationally, including here in Canada where several Canadian provinces either have a screening program in place or in development (7). Programs tend to support primary screening with the fecal occult blood test (FOBT) among those at average risk (7). Indeed, the recent Canadian Association of Gastroenterology position statement has emphasized that fecal immunochemical testing (FIT) or a highsensitivity guaiac-based FOBT should be used for programmatic averagerisk screening, with FIT being the test of choice (4), an approach that is also cost effective $(8,9)$. Nevertheless, the use of colonoscopy for primary CRC screening is on the rise in many jurisdictions, which has contributed to long wait times for colonoscopy. In the current issue of The Canadian Journal of Gastroenterology, McGregor et al (10) (pages 248-252) report on the results of their study aimed to inform the content and design of a mailed invitation for average-risk individuals to complete an FOBT while on the wait list for screening colonoscopy.

Focus groups were created through mailed invitation letters sent to 150 average-risk individuals randomly selected from the wait list for screening colonoscopy at the Forzani and MacPhail Colon Cancer Screening Centre in Calgary, Alberta. The purpose of the focus groups was to explore the reactions of average-risk individuals to different materials and strategies designed to encourage the completion of an FOBT while awaiting screening colonoscopy. Thirty-four individuals responded to the invitation, and 28 were ultimately available to attend one of three focus groups. The key findings from the focus groups were as follows: individuals were generally receptive to a mailed FOBT invitation, but the credibility of the materials sent was important and ideally associated with their family physician; brief letters without overuse of medical terminology were preferred; receipt soon after referral for colonoscopy along with a description of how the FOBT results would affect an individual's position on the waiting list appeared to increase the likelihood of a response; and including the FOBT kit itself along with supportive materials in the mail were considered to be useful.
\end{abstract}

There were limitations to this study that warrant consideration. The sample was comprised primarily of English-speaking, educated Caucasian individuals at a single academic institution. In addition, the number of individuals sampled was small, which may have limited the diversity of the opinions elicited. Finally, the overall response rate was low. As acknowledged by the authors, these factors have important implications in terms of the generalizability of the study findings.

Despite its limitations, the study performed by McGregor et al (10) suggests that average-risk individuals would be receptive to an organized CRC screening intervention with FOBT while awaiting colonoscopy. Furthermore, it provides some guidance on how to optimize 'buy in' of such an intervention among those facing long wait times for screening colonoscopy. As such, these findings deserve consideration as a wait list management strategy. However, as population-based CRC screening programs become more widespread and established with an accompanying increase in screening uptake, it is inevitable that wait times for colonoscopy will amplify. It is conceivable that average-risk individuals wait-listed for primary screening colonoscopy might only receive the procedure when their stool-based test is positive. As such, a strategy of FOBT while waiting for screening colonoscopy may simply be a short-term solution. Instead, perhaps we should use the findings of McGregor et al (10) to develop an optimized FOBT - or better yet, FIT-based - CRC screening program for average-risk individuals to determine who should be offered a colonoscopy in the first place, rather than as a means of managing an increasingly unmanageable wait list. It may be time to reconsider whether primary screening colonoscopy for the average-risk individual with a negative fecal-based screening test is something we can - or should - be offering, given our current demands and resource constraints.

\section{REFERENCES}

1. Wilson JMG, Junger G. Principles and Practice of Screening for Disease: WHO, 1968

2. U.S. Preventive Services Task Force recommendation statement. Screening for colorectal cancer. Ann Intern Med 2008;149:627-37.

3. Dominic OG, McGarrity T, Dignan M, Lengerich EJ. American College of Gastroenterology Guidelines for Colorectal Cancer Screening 2008. Am J Gastroenterol 2009;104:2626-7; author reply 2628-9.

4. Leddin DJ, Enns R, Hilsden R, Plourde V, Rabeneck L, Sadowski DC, Signh H. Canadian Association of Gastroenterology position statement on screening individuals at average risk for developing colorectal cancer: 2010. Can J Gastroenterol 2010;24:705-14.

5. Levin B, Lieberman DA, McFarland B, et al. Screening and surveillance for the early detection of colorectal cancer and adenomatous polyps, 2008: A joint guideline from the American Cancer Society, the US Multi-Society Task Force on Colorectal Cancer, and the American College of Radiology. Gastroenterology 2008;134:1570-95.

6. McGregor SE, Hilsden RJ, Li FX, Bryant HE, Murray A. Low uptake of colorectal cancer screening $3 \mathrm{yr}$ after release of national recommendations for screening. Am J Gastroenterol 2007;102:1727-35.

7. Ho C, Heitman S, Membe SK, et al. Computed tomographic colonography for colorectal cancer screening in an average risk population: Systematic review and economic evaulation (technology report 114). Ottawa: Canadian Agency for Drugs and Technologies in Health, 2008 <http://www.cadth.ca/> (Accessed on April 15, 2011).

8. Heitman SJ, Hilsden RJ, Au F, Dowden S, Manns BJ. Colorectal cancer screening for average-risk North Americans: An economic evaluation. PLoS Med 2010;7:e1000370.

9. Telford JJ, Levy AR, Sambrook JC, Zou D, Enns RA. The cost-effectiveness of screening for colorectal cancer. CMAJ 2010;182:1307-13.

10. McGregor SE, Ritvo P, Tinmouth J, et al. Reactions to a targeted intervention to increase fecal occult blood testing among average-risk adults waiting for screening colonoscopy. Can J Gastroenterol $2011 ; 25: 248-52$

Division of Gastroenterology, Department of Medicine, University of Calgary, Calgary, Alberta

Correspondence: Dr Steven J Heitman, Division of Gastroenterology, Department of Medicine, University of Calgary, 3280 Hospital Drive

Northwest, Room 6D27, Calgary, Alberta T2N 426. Telephone 403-592-5013, fax 403-592-5090,

e-mail steven.heitman@albertahealthservices.ca

Received and accepted for publication April 13, 2011 


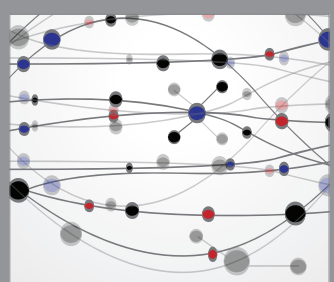

The Scientific World Journal
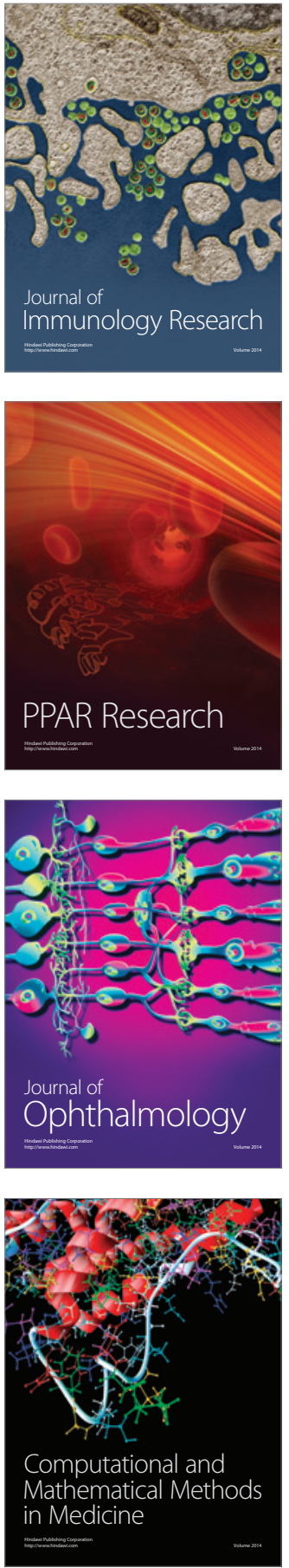

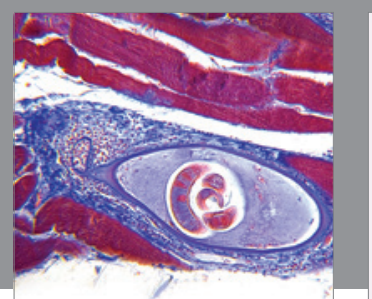

Gastroenterology Research and Practice

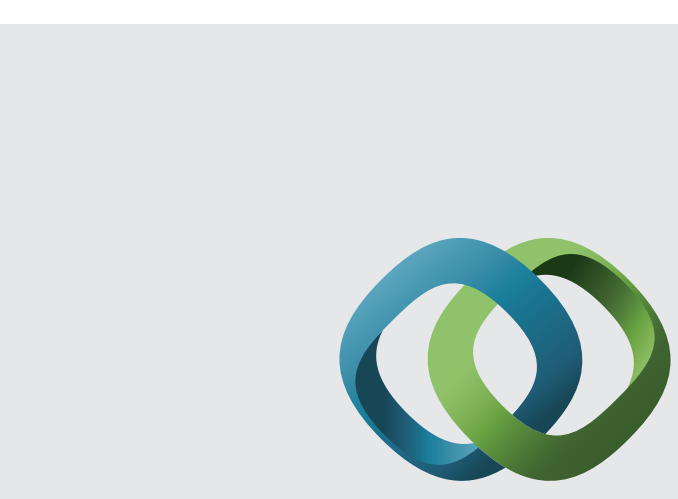

\section{Hindawi}

Submit your manuscripts at

http://www.hindawi.com
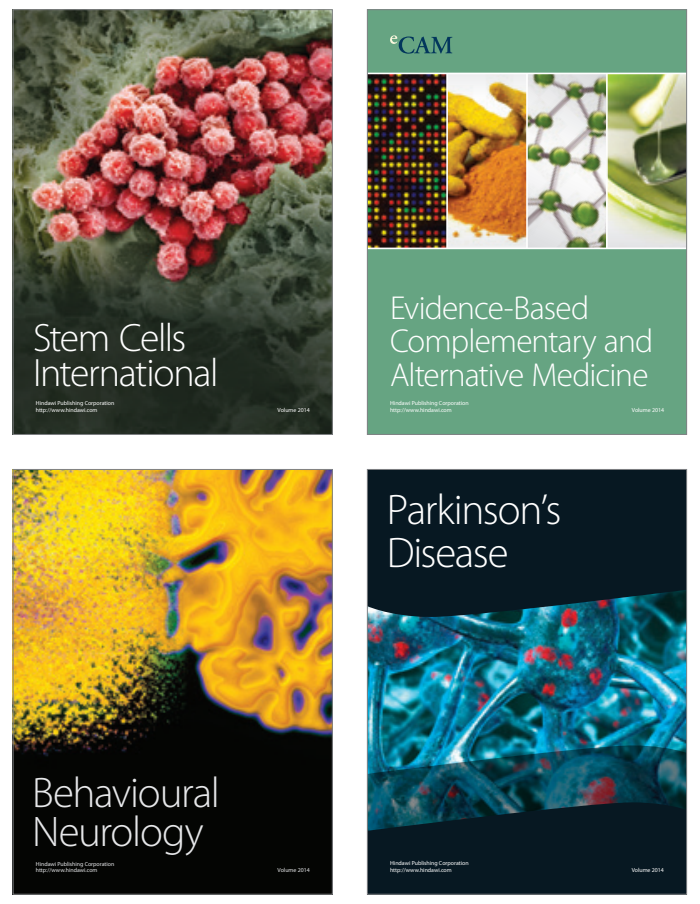
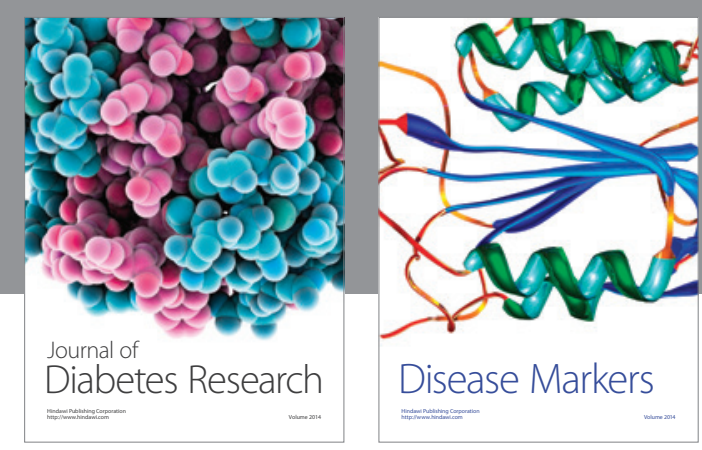

Disease Markers
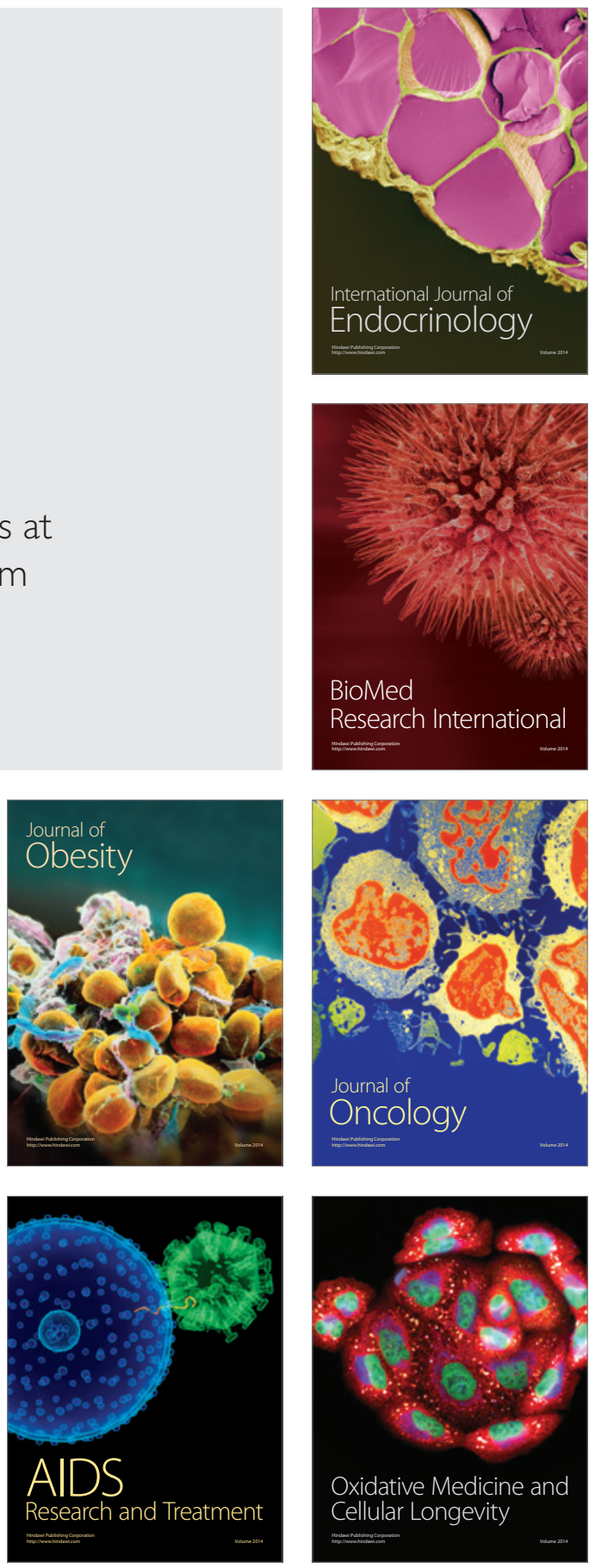